\title{
2-furyl(phenyl)methanol isolated from Atractilis gummifera rhizome exhibits anti-leishmanial activity
}

\author{
Solene Deiva ${ }^{\mathrm{a}}$, Lindsay Ferguson ${ }^{\mathrm{a}}$, Mostafa E. Rateb ${ }^{\mathrm{a}}$, Roderick Williams ${ }^{\mathrm{a}}$, Federico Brucoli ${ }^{\mathrm{b}, *}$

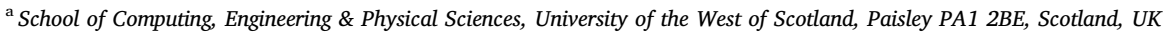 \\ ${ }^{\mathrm{b}}$ Leicester School of Pharmacy, De Montfort University, Leicester LE1 9BH, UK
}

\section{A R T I C L E I N F O}

\section{Keywords:}

Antileishmanial agents

Ent-kaurane diterpenoids

Structural characterisation

Leishmania donovani

Luciferase assay

Phenyl-furan chemical scaffold

\begin{abstract}
A B S T R A C T
We report for the first time the isolation of 2-furyl(phenyl)methanol (5) from the chloroform extracts of the Atractylis gummifera roots. A. gummifera is a thistle belonging to the Asteraceae family that produces the entkaurane diterpenoid glycoside atractyloside (ATR). ATR (1) was isolated and chemically modified to obtain its aglycone atractyligenin (2) and the methylated derivatives ATR-OMe (3) and genine-OMe (4). The compounds 1-5 were structurally characterised and evaluated against the intracellular amastigote, cultured within macrophages, and the extracellular promastigote of Leishmania donovani, the protozoan parasite responsible for the highly infective disease visceral leishmaniasis, which is fatal if untreated. The 2-furyl(phenyl)methanol 5 exhibited notable activity against the promastigote.
\end{abstract}

\section{Introduction}

Leishmaniasis (L) is a neglected tropical disease (NTD), affecting 12 million people in almost 90 countries and causing 50,000 deaths each year [1-3]. Leishmaniasis is generally grouped into three clinical forms, including cutaneous (CL), mucocutaneous and visceral leishmaniasis (VL) [4]. CL is the most common variant and, although self-healing, can create permanent disfiguring scars [5]. CL is prevalently caused by Leishmania amazensis, Leishmania major, Leishmania braziliensis, Leishmania mexicana and Leishmania panamensi [6]. On the other hand, VL (also known as kala azar), caused by Leishmania donovani and Leishmania infantum, is the most severe form of the infection and, if not treated, might result in widespread destruction of mucous membranes, visceral and haemopoetic organs, and ultimately death [7].

Although vaccines against the Leishmania parasites are currently being developed, the use of chemotherapeutic agents, such as miltefosine, panoromycin and pentavalent antimonials (sodium stibogluconate and meglumine antimoniate), remains, by far, the most effective treatment option [1,8-10]. Anti-leishmanial medicines with the exception of miltefosine are administered intravenously over prolonged periods of time. The rise of antimonial drug-resistant parasites, decadesold first-line drugs and low patient compliance, due to long drug regimens and unpractical administration routes, has led to high rates of treatment failure and relapses [7,11].

As a result, there is an urgent need to access and identify novel and diverse chemical scaffolds to support and improve the process of developing novel anti-leishmanial medicines. To this end, natural products continue to be a remarkable source of therapeutic leads [12] and tripterpenoids and ent-kaurane diterpenoid glycosides, commonly isolated from some Asteraceae and Annonaceae species, were shown to be active in vitro against trypanosomatids, such as Trypanosoma cruzi and T. brucei [13-15].

This finding prompted us to evaluate against protozoan parasites of the genus Leishmania (also belonging to the Trypanosomatida order) both aqueous and chloroform extracts of Atractylis gummifera, a thistle belonging to the Asteraceae family that grows throughout the Mediterranean region and is widely known for its acute toxicity [16]. The A. gummifera rhizome contains atractyloside 1 (ATR), a glucoside consisting of the tetracyclic ent-kaurane diterpene atractyligenin 2 attached through a $\beta$-linkage to the anomeric carbon of a D- $(+)$-glucose residue (Fig. 1) [17]. ATR exerts its biological activity by inhibiting the oxidative phosphorylation in the mitochondria of hepatocytes and proximal tubular epithelial cells, and has been extensively investigated for its pharmacological and chemical properties [18-20].

To our knowledge, A. gummifera metabolites have not been tested to date against Leishmania parasites and here we wish to report on the isolation, characterisation and anti-leishmanial activity of known plant active principles atractyloside (1) and atractyligenin (2), their methylated derivatives ATR-OMe (3) and atractyligenin-OMe (4), and 2-furyl (phenyl)methanol (5) that was found in the thistle rhizome's

\footnotetext{
* Corresponding author.

E-mail address: federico.brucoli@dmu.ac.uk (F. Brucoli).
} 


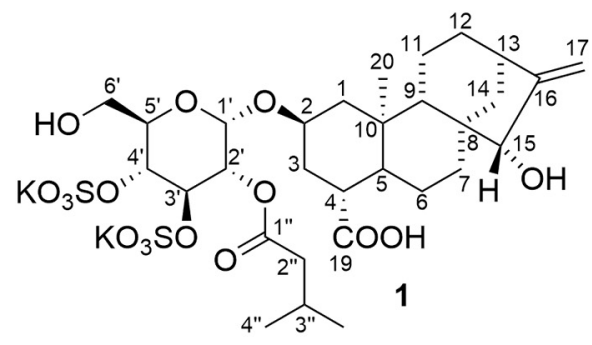<smiles>C=C1[C@H]2CC[C@@H]3[C@]4(C)C[C@@H](O)C[C@H](C(=O)O)C4CC[C@]3(C2)[C@H]1O</smiles>

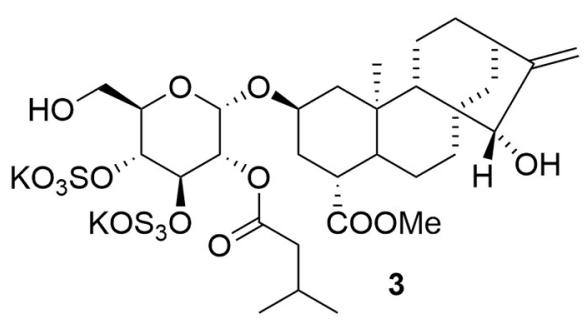<smiles>C=C1C2CC[C@@H]3[C@@]4(C)C[C@@H](O)C[C@H](C(=O)OC)C4CC[C@]3(C2)[C@H]1O</smiles>

4<smiles>OC(c1ccccc1)c1ccco1</smiles>

furan-2-yl(phenyl)methanol

5<smiles>N=C(N)c1ccc(-c2ccc(-c3ccc(C(=N)N)cc3)o2)cc1</smiles>

Fig. 1. Structures of atractyloside (1), its aglycone atractyligenin (2), their methyl ester derivates $\mathbf{3}$ and $\mathbf{4}$, and the 2-furyl(phenyl)methanol (5), which was isolated from the $\mathrm{CHCl}_{3}$ extracts of $A$. gummifera roots. Furamidine (DB75) is a pentamidine analogue bearing a core 2,5 disubstituted furan ring.

Table 1

${ }^{1} \mathrm{H}$ - and ${ }^{13} \mathrm{C}-\mathrm{NMR}$ data for compounds $5^{\mathrm{a}}$.

\begin{tabular}{lll}
\hline Position & $\delta_{\mathrm{H}}(J$ in Hz$)$ & $\delta_{\mathrm{C}}$ \\
\hline 2 & - & 141.5 \\
3 & $6.78 \mathrm{~d}(3.3), 1 \mathrm{H}$ & 115.6 \\
4 & $6.54 \mathrm{dd}(3.3,1.8)$ & 111.4 \\
5 & $7.71 \mathrm{~d}(1.3)$ & 144.8 \\
6 & $5.64 \mathrm{~d}(4.4)$ & 62.8 \\
7 & - & 135.7 \\
$8 / 12$ & $7.49 \mathrm{~d}(7.4) 2 \mathrm{H}$ & 126.4 \\
$9 / 11$ & $7.38 \mathrm{t}(7.5) 2 \mathrm{H}$ & 128.4 \\
10 & $7.32-7.30 \mathrm{~m} 1 \mathrm{H}$ & 127.8
\end{tabular}

${ }^{\mathrm{a}}$ Recorded in DMSO- $d_{6}, 600$ and $125 \mathrm{MHz}$.

chloroform extracts (Fig. 1). The compounds structures were established on the basis of spectroscopic methods, including 1D- and 2DNMR techniques $\left({ }^{1} \mathrm{H}-\right.$ and ${ }^{13} \mathrm{C}-\mathrm{NMR}$ spectra and COSY, HSQC, NOESY and $\mathrm{HMBC}$ experiments) and high-resolution mass spectrometry (HRMS). The luciferase assay was used to screen the compounds (1-5) against the two structural variants of Leishmania donovani, i.e., the amastigote non-motile form, which is found in the mononuclear phagocytes and circulatory systems of humans, and the promastigote (extracellular and motile) form, which is found in the alimentary tract of sand flies [21].

\section{Results and discussion}

\subsection{Chemistry}

The crushed rhizome of $A$. gummifera was treated with an aqueous- acetone solution in order to isolate atractyloside 1 (ATR), according to published methods [22,23]. ATR was isolated in good yield and its NMR spectra and MS analysis were in accordance with the literature data [17]. The aqueous-acetone rhizome mixture was then extracted with chloroform and the organic fraction was concentrated and subjected to column chromatography over normal phase silica gel and semi-preparative HPLC to afford 2-furyl(phenyl)methanol $\mathbf{5}$ as a pale yellow amorphous solid. The molecular formula of $\mathbf{5}$ was established as $\mathrm{C}_{11} \mathrm{H}_{10} \mathrm{O}_{2}$ by HR-ESI-MS, which showed the quasi molecular ion peak $[\mathrm{M}+\mathrm{H}]^{+}$at $m / z 175.0755$ (calculated for 174.0681). The IR spectrum showed absorptions for hydroxyl and aromatic (mono-substituted) groups at 3366 and $749 \mathrm{~cm}^{-1}$, respectively.

The ${ }^{1} \mathrm{H}$-NMR spectrum of 5 displayed characteristic up-field protons of a mono-substituted benzene ring at $\delta_{\mathrm{H}} 7.49(\mathrm{~d}, J=7.4 \mathrm{~Hz}, \mathrm{H}-8, \mathrm{H}-$ 12), 7.38 (t, $J=7.5 \mathrm{~Hz}, \mathrm{H}-9, \mathrm{H}-11$ ) and 7.32-7.30 (m, H-10) (Table 1). The most up-field singlet at $\delta_{\mathrm{H}} 7.71(\mathrm{~d}, J=1.3 \mathrm{~Hz}, \mathrm{H}-5)$ correlated with signals at $\delta_{\mathrm{H}} 6.54$ (dd, $\left.J=3.3,1.8 \mathrm{~Hz}, \mathrm{H}-4\right)$ and 6.78 (d, $J=3.3 \mathrm{~Hz}, \mathrm{H}-$ 3) in ${ }^{1} \mathrm{H}_{-}{ }^{1} \mathrm{H}$ COSY and NOESY experiments, and this was indicative of a 2-substituted furan ring.

One signal observed at $\delta_{\mathrm{H}} 5,64(\mathrm{~d}, J=4.4 \mathrm{~Hz}, \mathrm{H}-6)$, which HSBC correlated with $\delta_{\mathrm{C}} 62.8$, suggested the presence of an oxygenated $\mathrm{sp}^{3}$ methine bridge connecting the phenyl group with the furan ring. The complete linkage of the phenyl ring and its connection with the furan moiety via the methane bridge was resolved by the key HMBC correlations from $\mathrm{H}-6\left(\delta_{\mathrm{H}} 5,64\right)$ to C-8/12 $\left(\delta_{\mathrm{C}} 126.4\right), \mathrm{C}-7\left(\delta_{\mathrm{C}} 135.7\right)$ and C-2 ( $\left.\delta_{\mathrm{C}} 141.5\right)$, from H-3 $\left(\delta_{\mathrm{H}} 6.78\right)$ to C-4 $\left(\delta_{\mathrm{C}} 111.4\right)$ and C-5 (144.8), and from $\mathrm{H}-9 / 11\left(\delta_{\mathrm{H}} 7.38\right)$ to $\mathrm{C}-8 / 12\left(\delta_{\mathrm{C}} 126.4\right)$ and $\mathrm{C}-10\left(\delta_{\mathrm{C}} 127.8\right)$ (Fig. 2). 


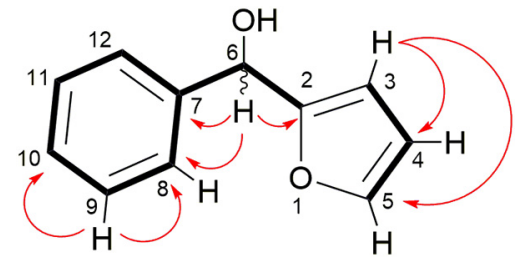

Fig. 2. Key HMBC (in red) and COSY (in bold) correlations of 5. (For interpretation of the references to colour in this figure legend, the reader is referred to the web version of this article.)

\subsection{Biology}

Compounds 1-5 were tested for cytotoxicity against transgenic firefly luciferase-expressing Leishmania donovani amastigote and promastigote, and bone marrow-derived macrophages from Balb/C mice. ATR 1, its derivatives 2-4 and the crude chloroform extracts of $A$. gummifera were incubated at different concentrations $(0.001-10 \mathrm{mM})$ with $L$. donovani promastigote and amastigote, cultured intracellularly within macrophages, for $72 \mathrm{~h}$ (Fig. 3). Residual ATP levels, or luciferase activity, against exogenous luciferin $(0.1 \mu \mathrm{g} / \mathrm{mL})$ were determined using a luminometer and the viability of L. donovani, expressed as percent of the no-drug control experiments, was subsequently derived.

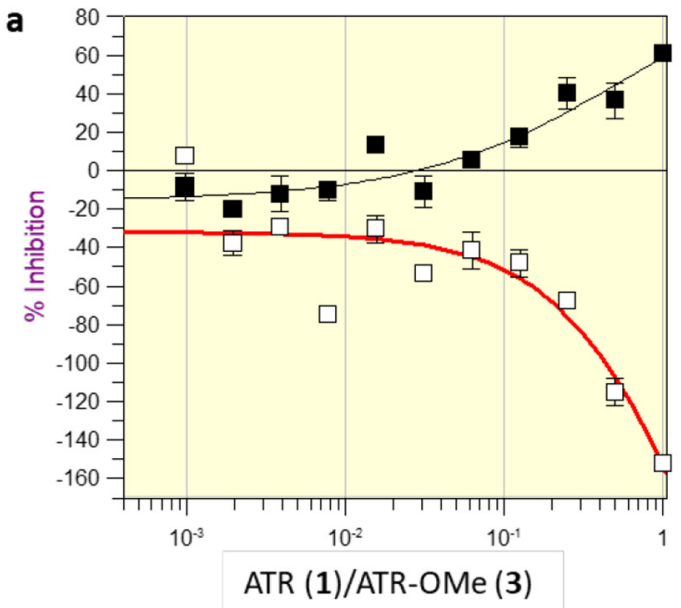

Atractyloside $\mathbf{1}$ and its genine $\mathbf{2}$ did not exhibit any anti-leishmanial or cytotoxic activity against macrophages, conversely, they appeared to stimulate the growth of the parasites in a dose-dependent fashion as illustrated in Fig. 3a (open squares, red lines). However, their methyl carboxylate derivatives 3 and $\mathbf{4}$ were found to inhibit the growth of $L$. donovani promastigote with $\mathrm{IC}_{50}$ (the dose that kills $50 \%$ of cells) values of $5 \mathrm{mM}$ and $0.23 \mathrm{mM}$, respectively (Table 2). Interestingly, the crude rhizome chloroform extracts showed anti-leishmanial activity with growth inhibitory concentrations of 0.059 and $0.88 \mathrm{mM}$ against the promastigote and amastigote forms, respectively (Table 2 ). This notable finding prompted us to analyse the composition of the chloroform extracts of the plant root and 2-furyl(phenyl)methanol $\mathbf{5}$ was identified as the chemical agent responsible for anti-parasitic activity. The newly isolated compound $\mathbf{5}$ was retested on its own and showed remarkable activity against the $L$. donovani promastigote $(0.029 \mathrm{mM})$, with relatively low toxicity against macrophages and high selectivity index $(\mathrm{SI}=345)$. Compound 5 retained biological activity, albeit at high concentration, also against the amastigote form of the parasite at $1 \mathrm{mM}$ $(\mathrm{SI}=10)$.

Chiral chromatography analysis of the 2-furyl(phenyl)methanol 5 isolated from the chloroform extract of the A. gummifera rhizome revealed the presence of two enantiomers. The configuration of the stereoisomers was assigned by comparing the HPLC elution order with previously reported data [24]. The first peak, which eluted at $25.4 \mathrm{~min}$,

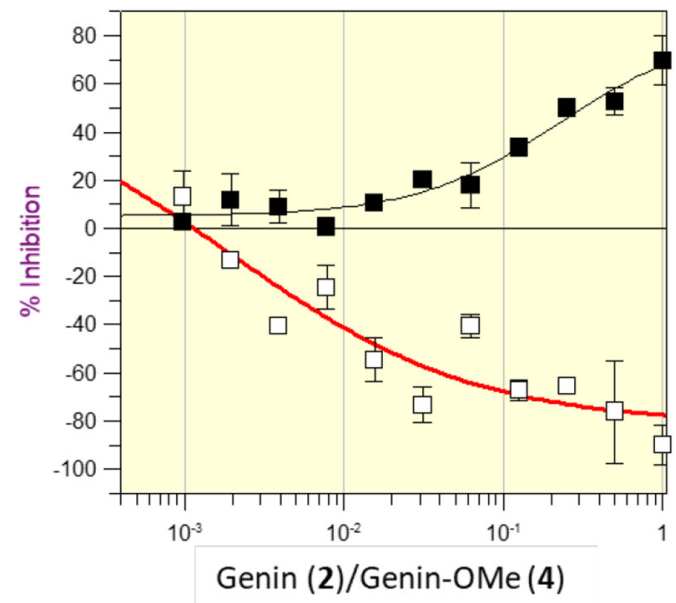

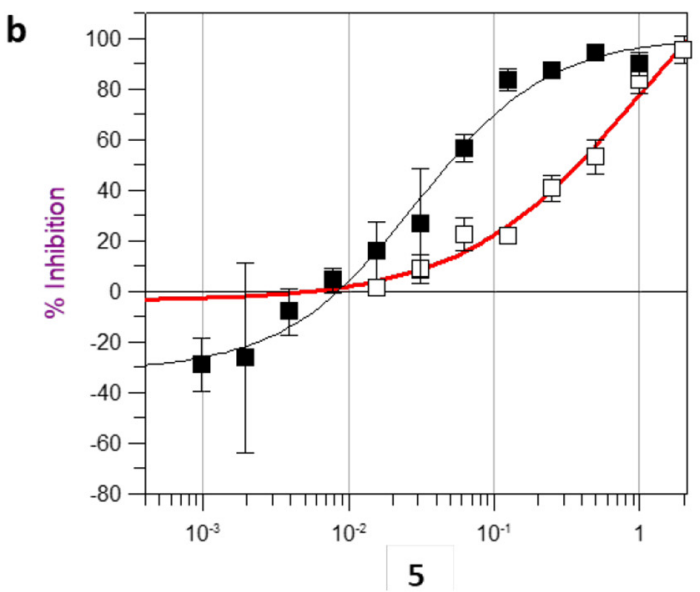

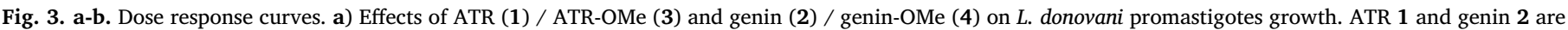

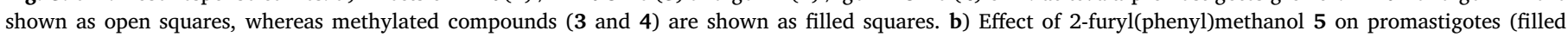

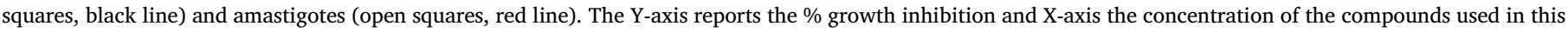
study. Concentrations are in $\mathrm{mM}$ and \% inhibition was determined using the luciferase assay protocol previously described [29]. 
Table 2

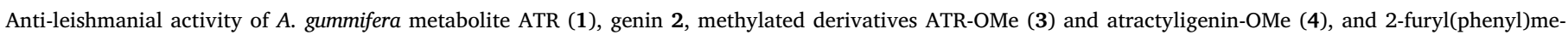
thanol (5).

\begin{tabular}{|c|c|c|c|c|c|}
\hline \multirow[b]{2}{*}{ Compound } & \multicolumn{3}{|c|}{ Cytotoxicity $\mathrm{IC}_{50}(\mathrm{mM})^{a}$} & \multirow[b]{2}{*}{$\mathrm{SI}_{\text {promastigote }}{ }^{c}$} & \multirow[b]{2}{*}{ SI $_{\text {amastigote }}{ }^{d}$} \\
\hline & Promastigotes & Amastigotes & Macrophages $^{b}$ & & \\
\hline ATR (1) & $\mathrm{N} / \mathrm{A}^{e}$ & N/A & N/A & - & - \\
\hline Genin (2) & N/A & N/A & N/A & - & - \\
\hline ATR-OMe (3) & $5.18 \pm 9.77$ & N/A & N/A & - & - \\
\hline Genin-OMe (4) & $0.23 \pm 0.16$ & N/A & N/A & - & - \\
\hline Crude $\mathrm{CHCl}_{3}$ extracts & $0.059 \pm 0.015$ & $0.88 \pm 0.34$ & $>10$ & $>169$ & $>11$ \\
\hline 5 & $0.029 \pm 0.006$ & $1.00 \pm 1.73$ & $>10$ & $>345$ & $>10$ \\
\hline
\end{tabular}

a $\mathrm{IC}_{50}$ is defined as the dose that kills $50 \%$ of cells.

b Bone marrow-derived macrophages from Balb/C mice.

c Selectivity Index $x_{\text {promastigote }}=\mathrm{IC}_{50}$ macrophages $/ \mathrm{IC}_{50}$ promastigotes.

d Selectivity Index ${ }_{\text {amastigote }}=\mathrm{IC}_{50}$ macrophages $/ \mathrm{IC}_{50}$ amastigotes.

e N/A - No activity at $10 \mathrm{mM}$. The experiments were carried out in triplicate.

was identified as the $R$ enantiomer, whereas the second peak with a retention time of $30.4 \mathrm{~min}$ corresponded to the $S$ enantiomer.

The 2-furyl(phenyl)methanol (5) exhibited moderate activity against $L$. donovani amastigote but was 30 -fold more active against the promastigote form of the parasite $(29 \mu \mathrm{M})$. The phenyl-furan scaffold is particularly rare in natural product frameworks and there are only few examples reported in the literature of secondary metabolites from plants and fungi containing this bis-aromatic unit. These include, but are not limited to, peplidiforone C (6) [25] from Hypericum peplidifolium, 3-hydroxy-1,4,7-trimethoxydibenzofuran (7) [26] from Hypericum revolutum ssp. and myrothecol (8) [27], a polyketide isolated from the fungus Myrothecium sp. GS-17 (Fig. 4). The latter (8), which contains a 1,3-dihydroisobenzofuran unit linked to a 2-furyl moiety, is closely related to the structure of the 2-furyl(phenyl)methanol (5) isolated from the chloroform fraction of A. gummifera. As a result, we postulate that $\mathbf{5}$ might be of polyketide biosynthetic origin with a pathway involving prenylation of a benzene substrate followed oxidation and synthase-mediated cyclisation via Michael addition mechanisms.

On the other hand, the phenyl-furan moiety is a privileged chemical scaffold present in the structure of a number of synthetic medicinal compound. For example, furamidine (DB75) [28] is a pentamidine analogue bearing a core 2,5-disubstitued furan ring, which was evaluated in phase III clinical trials for Human African trypanosomiasis (Fig. 1). As a result, further chemical modifications can be carried to the easily accessible 2-furyl(phenyl)methanol in order to furnish attractive anti-leishmanial chemical probes.

\section{Materials and methods}

\subsection{Experimental section}

\subsubsection{General experimental information}

${ }^{1} \mathrm{H}$ - and ${ }^{13} \mathrm{C}$-NMR spectra were acquired using Bruker Avance $400 \mathrm{MHz}$ and Avance III $600 \mathrm{MHz}$ NMR spectrometers. Chemical shifts are reported in parts per million (ppm) with the solvent resonance as the internal standard and coupling constants $(J)$ are quoted in Hertz (Hz). Spin multiplicities are described as s (singlet), bs (broad singlet), $d$ (doublet), dd (doublet of doublets), t (triplet), q (quadruplet), and $\mathrm{m}$ (multiplet). Optical rotations were determined on a Bellingham and Stanley digital polarimeter ADP 410.

Infrared spectra were acquired on a Perkin Elmer FT-IR Spectrometer (Spectrum 1000) and absorbance frequencies are reported in reciprocal centimeters $\left(\mathrm{cm}^{-1}\right)$.

LC-MS analysis was conducted on an Agilent 6100 series Quadrupole LC-MS system coupled with a G4220A 1290 binary pump/ $\mathrm{DAD}$, using an Agilent Zorbax SB-C19 reverse-phase column $(2.1 \times 50 \mathrm{~mm})$ with a flow rate of $1 \mathrm{~mL} \mathrm{~min}^{-1}$. Solution B was kept at $5 \%$ for $0.8 \mathrm{~min}$, then a gradient was applied up to $100 \% \mathrm{~B}$ at $6.6 \mathrm{~min}$ and solution $\mathrm{B}$ was held at $100 \%$ for $1.6 \mathrm{~min}$, then $\mathrm{B}$ was reverted back to $5 \%$ until 10 min. Eluent A: $\mathrm{H}_{2} \mathrm{O} / 0.1 \%$ formic acid; eluent $\mathrm{B}: \mathrm{CH}_{3} \mathrm{CN} /$ $0.1 \%$ formic acid.

HR-MS data were recorded on Thermo LTQ Orbitrap coupled to an HPLC system (PDA detector, PDA autosampler, and pump). The following conditions were used: capillary voltage of $45 \mathrm{~V}$, capillary temperature of $260^{\circ} \mathrm{C}$, auxiliary gas flow rate of $10-20$ arbitrary units, sheath gas flow rate of $40-50$ arbitrary units, spray voltage of $4.5 \mathrm{kV}$, and mass range of 100-2000 amu (maximal resolution of 30,000). For LC/MS, a Sunfire C18 analytical HPLC column $(5 \mu \mathrm{m}$, $4.6 \mathrm{~mm} \times 150 \mathrm{~mm}$ ) was used with a mobile phase of 0 to $100 \% \mathrm{MeOH}$

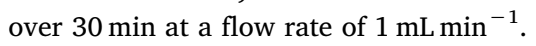

Chiral HPLC analysis was performed using a Daicel Chiralcel OD analytical column $(250 \times 4.6 \mathrm{~mm}, 10 \mu \mathrm{m})$ and UV detection was monitored at $230 \mathrm{~nm}$.

TLC and preparative TLC were performed on Merck Silicagel $60 \mathrm{~F}_{254}$ aluminum sheets. TLC system 1: Si gel, EtOAc:acetone: $\mathrm{H}_{2} \mathrm{O}: \mathrm{HOAc} /$ 5:3:1:1, sprayed with a vanillin- $\mathrm{H}_{2} \mathrm{SO}_{4}$ solution prepared by dissolving $15 \mathrm{~g}$ of vanillin in $250 \mathrm{~mL}$ of EtOH with $0.01 \%$ conc $\mathrm{H}_{2} \mathrm{SO}_{4}$. TLC system 2: Si gel, hexane: EtOAc / 9:1. TLC system 3: Si gel, $\mathrm{CHCl}_{3}: \mathrm{MeOH}: \mathrm{HOAc}$ / 8:2:0.5.

Purifications of the intermediates and final products were

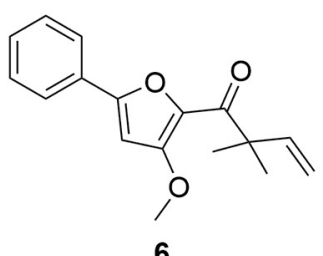

peplidiforone $\mathrm{C}$

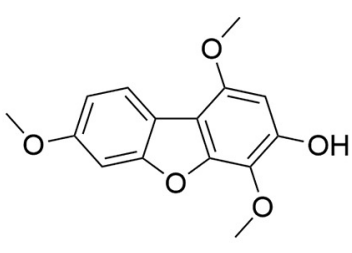

7

3-hydroxy-1,4,7-trimethoxydibenzofuran

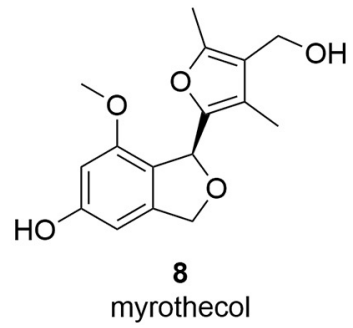

myrothecol

Fig. 4. Chemical structures of natural products bearing phenyl-furan moieties, including peplidiforone C (6), 3-hydroxy-1,4,7-trimethoxydibenzofuran (7) and myrothecol (8) isolated from Hypericum peplidifolium, Hypericum revolutum ssp. and the fungus Myrothecium sp. GS-17, respectively. 
conducted using an Interchim puriflash 4100 automatic purification machine. The crude compounds were injected into the system at a rate of $250 \mathrm{~mL} / \mathrm{min}$ at $100 \mathrm{bar}$, using a $15 \mu \mathrm{g}$ silica, high-capacity columns.

All chemicals were purchased from Fisher Scientific, Sigma Aldrich and Merck Chemicals, and used without further purification.

\subsubsection{Plant material}

The A. gummifera rhizomes were identified through morphological analysis and collected on 19/03/2014 by Professor Francesco Maria Raimondo in Piana degli Albanesi, Loc. Maganoce, Palermo, Italy. Fresh rhizomes were shipped to UK and stored at $-20^{\circ} \mathrm{C}$.

\subsubsection{Extraction and isolation}

The A. gummifera rhizomes $(439.64 \mathrm{~g})$ were cut and blended to obtain a coarse powder, which was initially extracted $(1 \mathrm{~L} / 100 \mathrm{~g})$ with acetone at $40^{\circ} \mathrm{C}$ for $2 \mathrm{~h}$. The powdered roots were further extracted three times with an acetone:water $(9: 1)$ mixture $(0.5 \mathrm{~L} / 100 \mathrm{~g})$ for $1 \mathrm{~h}$ each time. The four fractions were combined and evaporated under reduced pressure at a temperature below $40^{\circ} \mathrm{C}$ and condensed to $350 \mathrm{~mL}$ to give a dark-green oily residue, which was extracted with $\mathrm{CHCl}_{3}(3 \times 500 \mathrm{~mL}$ and $1 \times 150 \mathrm{~mL})$. The organic fractions were combined, filtered and evaporated at a reduced pressure to yield a brown oil $(1.052 \mathrm{~g})$, which was analysed to identify novel secondary metabolites.

3.1.3.1. Aqueous phase. The aqueous phase was concentrated to $500 \mathrm{~mL}$ at a reduced pressure at $40{ }^{\circ} \mathrm{C}$. A $20 \%$ aqueous solution of $\mathrm{KCl}(100 \mathrm{~mL})$ was then added and a white precipitate, containing ATR, was filtered off and washed with cold water. The mother solution was kept a $0-4{ }^{\circ} \mathrm{C}$ overnight and more precipitate was formed. A total of $3.750 \mathrm{~g}$ of ATR 1 ( $0.85 \%$ yield) was recovered as a pale yellow solid, which was characterised by TLC $\left(R_{f}=0.45\right.$, purple, TLC system 1$)$, LCMS and ${ }^{1} \mathrm{H}$-NMR spectroscopy. NMR spectral data were identical to previously analysed pure sample of ATR [17].

3.1.3.2. Organic solvent phase. The brown oil $(1.052 \mathrm{~g})$ was subjected to column chromatography over silica gel column with $0.5 \% \mathrm{MeOH}$ in $\mathrm{CHCl}_{3}$ to yield four fractions Fr. 1-4. Further purification of Fr 3 (46 mg) by preparative TLC (hexane:ethyl acetate - 9.5:0.5) allowed the isolation of pure $5\left(R_{\mathrm{f}}=0.29\right.$, TLC system 2$)$ as a pale yellow solid (3.5 mg).

\subsubsection{Synthetic procedures}

The physical and spectral data of compounds 1 were identical to those of pure samples previously isolated [17]. Compounds 2, 3 and 4 were prepared according to published procedures and their physical and spectroscopic data agreed with those reported in the literature [22].

Hydrolysis of ATR 1 to give atractyligenin 2. A solution of $500 \mathrm{mg}$ of ATR (1) in $20 \% \mathrm{KOH}$ in water $(5 \mathrm{~mL})$ was heated under reflux for $8 \mathrm{~h}$. The solution was acidified with $20 \% \mathrm{HCl}$ to $\mathrm{pH}=4$ at $0{ }^{\circ} \mathrm{C}$ and the solvent evaporated under reduced pressure. The residue was purified by column flash chromatography over silica gel to give $187 \mathrm{mg}$ ( $94 \%$ yield) of pure genin $2\left(R_{\mathrm{f}}=0.17\right.$, TLC system 3$)$ as a white solid. $[\alpha]_{20}{ }^{\mathrm{D}}-145$ (c 0.2, EtOH); ESIMS $m / z$ (negative mode) $319[\mathrm{M}-\mathrm{H}]^{-}$.

General procedure for the synthesis of 3 and 4 . To a solution of the desired compound ( 1 and 2 ) in a mixture of dry THF:MeOH / 5:3 (8 mL) was added TMSCHN $\mathrm{T}_{2}$ (1.5 equiv., $2 \mathrm{M}$ in $\mathrm{Et}_{2} \mathrm{O}$ ) dissolved in dry $\mathrm{MeOH}$ $(0.5 \mathrm{~mL})$ at $-40{ }^{\circ} \mathrm{C}$ over $5 \mathrm{~min}$. The reaction was allowed to reach room temperature and react for $4 \mathrm{~h}$. The reaction mixture was filtered off through a silica pad and eluted with $\mathrm{MeOH}(15 \mathrm{~mL})$ to give the desired product ( 3 and 4 ) that were judged pure by analysis of TLC, LC-MS, NMR, and IR spectra.

Atractyloside methyl ester (ATR-OMe) 3. Starting from $220 \mathrm{mg}$ (0.303 mmol) of ATR (1), $197 \mathrm{mg}(0.266)$ of 3 were obtained as a pale yellow solid ( $88 \%$ yield).
Atractyligenin methyl ester (genin-OMe) 4. Starting from $130 \mathrm{mg}$ $(0.406 \mathrm{mmol})$ of atractyligenin $2,110 \mathrm{mg}(0.329 \mathrm{mmol})$ of 4 were obtained as a white amorphous solid ( $81 \%$ yield). $R_{\mathrm{f}}=0.32$, purple, (TLC $=20 \% \mathrm{MeOH}$ in $\mathrm{CHCl}_{3}$, stained with vanillin- $\mathrm{H}_{2} \mathrm{SO}_{4}$ solution). $[\alpha]_{20}{ }^{\mathrm{D}}-141$ (c 0.2, EtOH); ESIMS $m / z$ (negative mode) $333[\mathrm{M}-\mathrm{H}]^{-}$. ${ }^{1} \mathrm{H}-\mathrm{NMR}(600 \mathrm{MHz}, \mathrm{MeOD}) \delta_{\mathrm{H}} 5.18$ (bs, $1 \mathrm{H}, \mathrm{H}-17 \alpha$ ), 5.08 (bs, $1 \mathrm{H}, \mathrm{H}-$ $17 \alpha$ ), 3.97 (bs, 1H, H-2), 3.77 (bs, 1H, H-15), 3.65 (s, 3H, $\mathrm{OCH}_{3}$ ), 2.71 (bs, 1H, H-13), 2.65-2.49 (m, 1H, H-4).

2-furyl(phenyl)methanol5. IR $\nu_{\max }$ (golden gate) $\mathrm{cm}^{-1} 3366,2925$, 2853, 1641, 1455, 1210, 1032, 969, 749. ${ }^{1} \mathrm{H}-\mathrm{NMR}$ and ${ }^{13} \mathrm{C}-\mathrm{NMR}$ (DMSO- $d_{6}$ ) please refer to Table 1; ESIMS $\mathrm{m} / \mathrm{z}$ (positive mode) 175.01 $[\mathrm{M}+\mathrm{H}]^{+}$; HRMS calculated for $\mathrm{C}_{11} \mathrm{H}_{10} \mathrm{O}_{2}$ 174.0681, found 175.0755 $[\mathrm{M}+\mathrm{H}]^{+}$. Chiral HPLC (Chiralcel OD, $2 \%$ isopropanol in hexane, flow rate $=1 \mathrm{~mL} \mathrm{~min}{ }^{-1}, \lambda=230 \mathrm{~nm}$ ): $\mathrm{R} t_{\mathrm{R}}=25.4 \mathrm{~min}$ for enantiomer $S$ and $\mathrm{R} t_{\mathrm{R}}=30.4 \mathrm{~min}$ for enantiomer $R$. The configuration of the enantiomers was assigned by comparing the HPLC elution order with previously published data [24].

\section{Biology}

\subsection{Parasite lines and cell culture microorganisms and growth conditions}

Luciferase-expressing transgenic Leishmania donovani LV82 promastigotes and amastigotes, within macrophage derived from bone marrow, were cultured in M199 and RPMI1640 medium (Gibco(C), supplemented with $20 \% v / v$ heat-inactivated foetal calf serum (FCS) (GibcoC), and 1\% penicillin streptomycin (Pen/Strep; Gibco (C) at $25^{\circ} \mathrm{C}$ [29].

Amastigotes of these lines were cultured within macrophage derived from bone marrow. The bone marrow derived macrophage were extracted as non-differentiated monocytes from bone marrow of the femur, cultured in Dulbecco's modified eagle medium (DMEM, Invitrogen) supplemented with $10 \% v / v$ FCS, 1\% pen/strep, 30\% $v / v$ cell supernatant and 1\% L-glutamine for 7-10 days, after which they were transferred to RPMI 1640 medium supplemented with 10\% FCS $(v / v), 1 \%$ pen/strep $(\mathrm{v} / \mathrm{v})$ and L-glutamine. Viability of macrophage was determined with the Trypan blue assay [29] prior to use for in vitro luminescence assay of intramacrophage amastigotes.

\subsection{In vitro Luminescence assay}

The previously reported luciferase assay [30] was used to estimate the cytotoxic effect of the compounds used in this study against transgenic L. donovani promastigotes and amastigotes. For promastigotes, the assay was carried in a 96 well format and $1 \times 106 \log$ phase promastigotes, with or without drugs at a concentration determined by the experimental protocol in a final volume of $100 \mu \mathrm{L}$, were incubated for $72 \mathrm{~h}$ at $26^{\circ} \mathrm{C}$. The cell viability was estimated by adding $0.5 \mu \mathrm{g} / \mathrm{mL}$ of luciferine to the assay plate and the luminescence was measured with the IVIS bio-imaging platform. Luminescence of drug-treated wells relative to their no drug control expressed as a percentage was used as a measure of cell viability.

For amastigotes, $10^{5}$ activated bone derived macrophages were incubated for $24 \mathrm{~h}$ in a 96 well plate at $37{ }^{\circ} \mathrm{C}, 5 \% \mathrm{CO}_{2}$ to adhere to the bottom of the well. Subsequently, the macrophages were infected with promastigotes at a ratio promastigotes:macrophage of 20:1, and incubated further for $24 \mathrm{~h}$ to allow phagocytosis of the parasites. After the extracellular parasites were washed out, the drugs were added to the wells at concentrations determined by the experimental protocol for $72 \mathrm{~h}$, and the viability was estimated as described for promastigotes. The data presented are derived from independent experiments done in triplicate. Dose response curves were used to estimate the $\mathrm{IC}_{50}$.

\section{Macrophage cellular toxicity}

The $\mathrm{IC}_{50}$ of macrophage for the compounds used in this study was 
estimated using the alamar blue assay. Briefly, macrophages (10 [5]) were incubated with different concentrations on drugs determined by the experimental protocol for $72 \mathrm{~h}$. Viability was estimated by adding alamar blue and incubating the macrophages further for $6 \mathrm{~h}$. Absorbance readings at $595 \mathrm{~nm}$ and $570 \mathrm{~nm}$ were used to estimate cell viability as described for promastigotes. Dose response curves were used to estimate the $\mathrm{IC}_{50}$. The selectivity indices were estimated by expressing the $\mathrm{IC}_{50}$ of macrophages to $\mathrm{IC}_{50}$ on $\mathrm{L}$. donovani amastigotes intracellularly within macrophage or $\mathrm{IC}_{50}$ of promastigotes.

\section{Acknowledgement}

We thank Tenovus Scotland for financial support (Tenovus Project S14-07).

\section{Declaration of Competing Interests}

The authors declare that they have no known competing financial interests or personal relationships that could have appeared to influence the work reported in this paper.

\section{Appendix A. Supplementary data}

${ }^{1} \mathrm{H}$ - and ${ }^{13} \mathrm{C}$-NMR spectra. This material is available free of charge via the Internet at

https://doi.org/10.1016/j.fitote.2019.104420

\section{Author information}

*To whom correspondence should be addressed: Dr. F. Brucoli. Email:Federico.brucoli@dmu.ac.uk; orcid.org/ 0000-0001-8661-2910. Tel. 0044 116,257 7443.

\section{References}

[1] Wkly Epidemiol Rec 2018, 93, 521-540.

[2] I. Kevric, M.A. Cappel, J.H. Keeling, Dermatol. Clin. 33 (2015) 579-593.

[3] H.E. Mableson, A. Okello, K. Picozzi, S.C. Welburn, PLoS Negl. Trop. Dis. 8 (2014) e2800.
[4] M. Akhoundi, K. Kuhls, A. Cannet, J. Votypka, P. Marty, P. Delaunay, D. Sereno, PLoS Negl. Trop. Dis. 10 (2016) e0004349.

[5] M.Z. Handler, P.A. Patel, R. Kapila, Y. Al-Qubati, R.A. Schwartz, J. Am. Acad. Dermatol. 73 (2015) 911-926 (927-928).

[6] B.L. Herwaldt, Lancet 354 (1999) 1191-1199.

[7] P.D. Ready, Clin Epidemiol 6 (2014) 147-154.

[8] J. Alvar, I.D. Velez, C. Bern, M. Herrero, P. Desjeux, J. Cano, J. Jannin, M. den Boer, W.H.O.L.C. Team, PLoS One 7 (2012) e35671.

[9] K. Jain, N.K. Jain, J. Immunol. Methods 422 (2015) 1-12.

[10] H.W. Murray, J.D. Berman, C.R. Davies, N.G. Saravia, Lancet 366 (2005) 1561-1577.

[11] M. Rama, N.V. Kumar, S. Balaji, Pharm Pat Anal 4 (2015) 37-56.

[12] L.G. Rocha, J.R. Almeida, R.O. Macedo, J.M. Barbosa-Filho, Phytomedicine 12 (2005) 514-535.

[13] J.P. Leite, A.B. Oliveira, J.A. Lombardi, J.D. Filho, E. Chiari, Biol. Pharm. Bull. 29 (2006) 2307-2309.

[14] R. Batista, J.L. Humberto, E. Chiari, A.B. de Oliveira, Bioorg. Med. Chem. 15 (2007) 381-391.

[15] T.S. Tiuman, A.O. Santos, T. Ueda-Nakamura, B.P.D. Filho, C.V. Nakamura, Int. J. Infect. Dis. 15 (2011) e525-e532.

[16] C. Daniele, S. Dahamna, O. Firuzi, N. Sekfali, L. Saso, G. Mazzanti, J. Ethnopharmacol. 97 (2005) 175-181.

[17] F. Brucoli, M.T. Borrello, P. Stapleton, G.N. Parkinson, S. Gibbons, J. Nat. Prod. 75 (2012) 1070-1075.

[18] P. Roux, A. Le Saux, C. Fiore, C. Schwimmer, A.C. Dianoux, V. Trezeguet, P.V. Vignais, G.J. Lauquin, G. Brandolin, Anal. Biochem. 234 (1996) 31-37.

[19] E. Pebay-Peyroula, C. Dahout-Gonzalez, R. Kahn, V. Trezeguet, G.J. Lauquin, G. Brandolin, Nature 426 (2003) 39-44.

[20] C. Fiore, V. Trezeguet, A. Le Saux, P. Roux, C. Schwimmer, A.C. Dianoux, F. Noel, G.J. Lauquin, G. Brandolin, P.V. Vignais, Biochimie 80 (1998) 137-150.

[21] W.W. Zhang, Matlashewski, G. Proc. Natl. Acad. Sci. 94 (1997) 8807-8811.

[22] B. Danieli, B. Gabetta, A. Bonati, E. Bombarde, Phytochemistry 2 (1972) 3501-3504.

[23] S. Rosselli, M. Bruno, A. Maggio, G. Bellone, T.H. Chen, K.F. Bastow, K.H. Lee, J. Nat. Prod. 70 (2007) 347-352.

[24] G. Lu, F.Y. Kwong, J. Ruan, Y. Li, A.S. Chan, Chem. Eur. J. 12 (2006) 4115-4120.

[25] S.A. Fobofou, C.R. Harmon, A.H. Lonfouo, K. Franke, S.M. Wright, L.A. Wessjohann, Phytochemistry 124 (2016) 108-113.

[26] W.K. Shiu, S. Gibbons, Phytochemistry 70 (2009) 403-406.

[27] T. Liu, J. Zhu, S.Y. Zhang, Z.L. Li, L.P. Guan, H.Q. Pan, X. Wu, J. Bai, H.M. Hua, Molecules 18 (2013) 15126-15133.

[28] M.F. Paine, M.Z. Wang, C.N. Generaux, D.W. Boykin, W.D. Wilson, H.P. De Koning, C.A. Olson, G. Pohlig, C. Burri, R. Brun, G.A. Murilla, J.K. Thuita, M.P. Barrett, R.R. Tidwell, Curr. Opin. Investig. Drugs 11 (2010) 876-883.

[29] R. Freshney, Culture of Animal Cells: A Manual of Basic Technique, P, 117 Alan R. Liss, Inc., New York, 1987.

[30] M. Alsaadi, J.L. Italia, A.B. Mullen, M.R. Kumar, A.A. Candlish, R.A. Williams, C.D. Shaw, F. Al Gawhari, G.H. Coombs, M. Wiese, A.H. Thomson, J. Control. Release 160 (2012) 685-691. 